Neth. J. Agric. Sci., 17 (1969): 41-49

\title{
On measuring properties of soils by thermal methods with special reference to the contact method
}

\section{J. Stigter}

Laboratory of Physics and Meteorology, Agricultural University, Wageningen, The Netherlands

Received 13 September, 1968

\begin{abstract}
Summary
Problems are discussed which limit the accuracy of determinations of thermal properties of soils, and also of determinations of the moisture content by thermal methods. Conditions to be satisfied before a method is applicable in the field are given. From these it has to be concluded that nearly all thermal field methods meet with several objections. On the basis of this review an explanation is given of the limitations set to application of the contact method in the field.
\end{abstract}

\section{Introduction}

The thermal properties of soils are of great importance to agriculture, especially in relation to temperature and heat flux in the root zone. In studies on energy and water balances the highest interest in their actual values is shown. The connection between thermal properties and moisture content of a soil layer has been used to determine the latter in the field from a calibration curve, obtained in the laboratory. The thermal parameters $\lambda$, the thermal conductivity and $C$, the heat capacity per unit volume, depend mainly on soil constituents, soil texture, porosity and moisture content. Difficulties in obtaining reliable values of $\lambda$ and $C$ do arise from a.o. the inhomogeneity of natural soils.

In relation to soil temperature this was emphasized by Lettau (1954) and reviewed by Blanc (1958). As to measurements of soil moisture de Vries (1959) reviewed experiments using thermal methods.

This paper deals with a review of conditions necessary for the measurements of $\lambda, \mathbf{C}$, their quotient the thermal diffusivity $\mathrm{a}=\lambda / \mathrm{C}$ and their product the contact coefficient $\mathrm{b}=\lambda \mathrm{C}$, by a direct method in the field. On the basis of this review the implications concerning a recently developed method are explained. Results with this method on homogeneous dry soils in the laboratory and some preliminary field determinations have already been reported (van Wijk, 1964, 1967; van Wijk et al., 1967; Schneider, 1967) and more recently a survey of the applicability on homogeneous solids and an extension of the mathematical theory was given by the present author (Stigter, 1968). Outdoors the method was intended to measure the contact coefficient and the moisture content in the first few centimeters of soil as well as the heat flux near the surface. The limitations on application, imposed by natural soil conditions, are discussed at the end of the paper. 


\section{Determination of thermal properties}

General remarks. As is well known, the thermal conductivity $\lambda$ of any substance, whether it is a gas, a liquid, or a solid, is defined by the fundamental law of conduction, the so called law of Fourier, which in one dimension may be stated as

$\mathrm{H}(\mathrm{z}, \mathrm{t})=-\lambda \frac{\delta \Theta(\mathrm{z}, \mathrm{t})}{\delta \mathrm{z}}$

$H(z, t)$ being the heat flux density at 'depth' $z$ and at time $t, \Theta(z, t)$ being the temperature there. All derivatives in this paper are partial derivatives.

Defining $\mathrm{C}$ as the quantity of heat necessary to raise the temperature of a unit volume by $1^{\circ} \mathrm{C}$ (it is as such the product of specific heat $\mathrm{c}$ and specific mass $\varrho$ ) and considering the change of heat flux, existing in the z-direction only, and the total gain of heat in such a volume, per unit of time, one obtains:

$\mathrm{C} \frac{\delta \Theta(\mathrm{z}, \mathrm{t})}{\delta \mathrm{t}}=-\frac{\delta \mathrm{H}(\mathrm{z}, \mathrm{t})}{\delta \mathrm{z}}$

A heat flux density may be caused by conduction, convection and radiation. In nontransparent solids only conduction takes place. As mentioned by de Vries (1952a) almost the same holds true with regard to dry granular materials. Radiation may normally be neglected for temperatures under $100^{\circ} \mathrm{C}$ and the influence of convection is generally low if the dimensions of the grains are smaller than 1 to $2 \mathrm{~mm}$. Two exceptions have been observed with moist soil. Firstly $\lambda$ was found to change when $\delta \Theta / \delta \mathrm{z}$ was enlarged (eq. 1) in nearly saturated sandy soil, due to convection. Secondly latent heat may be transported, a phenomenon with which we will deal later on.

If no internal heat sources or sinks exist, the partial differential equation of heat conduction in an isotropic and homogeneous solid, whether porous or not, is obtained by combining eqs. (1) and (2):

$\frac{\delta \Theta(\mathrm{z}, \mathrm{t})}{\delta \mathrm{t}}=\frac{\lambda}{\mathrm{C}} \frac{\delta^{2} \Theta(\mathrm{z}, \mathrm{t})}{\delta \mathrm{z}^{2}}$

If a heat source (or sink) is present in the volume a source function $Q(x, y, z, t)$ must be added.

As can be read in textbooks on agricultural physics (see e.g. van Wijk, 1963) C may be calculated with an accuracy of $\pm 5 \%$, when the volume fractions of the various soil components are known. If no swelling or shrinkage occurs and no heat is used for wetting during the uptake or the loss of water, heat capacity changes linearly with moisture content. No methods however are available of measuring directly the heat capacity 'in situ' in the field. The values for the soil components have always been obtained by the common calorimetric methods. Therefore no methods of determining moisture content exist which make use of the relation with volumetric heat capacity.

The way in which $\lambda$ can be approximately calculated was shown by de Vries (1952a, $1952 b$ ). He derived relations between the thermal conductivity of a granular material and the thermal conductivities and volume fractions of its constituents. Shape and 
packing of the granules have to be known. The accuracy of the calculated values varies between 5 and $20 \%$.

For the measurement of $\lambda$, a or $b$ we have to use a solution of eq. (3) with appropriate initial and boundary conditions, depending on the measuring device. As can be seen from eqs. (1) and (2) it is always necessary to make use of the determination of existing heat fluxes or to introduce a heat flux by creation of a temperature difference with the help of the device. Difficulties concerning the use of existing heat fluxes by working with a Fourier analysis of actual diurnal or annual subsoil temperature variations are mentioned by Lettau (1954). One more example of the field problem here is the effect of substantial thermally induced moisture transfer by the diurnal temperature wave (Cary, 1967). Some features concerning direct methods in the field will be treated subsequently below.

The induced heat flux. At first we must distinguish between stationary and nonstationary methods. The former are predominantly in use for accurate thermal conductivity measurements in gases, fluids and dry solids. As $\delta \mathrm{H}(\mathrm{z}, \mathrm{t}) / \delta \mathrm{z}$ in eq. (2) is zero, $\lambda$ can be found directly from eq. (1). The employed 'plates', between which the constant heat flux is maintained, are however not suited for use in the field. The soil has to be disturbed in such a way that the natural situation is totally transformed. Moreover moisture transfer has to remain within reasonable limits under the unavoidable temperature gradients. Moisture transport, chiefly by a process of vapour distillation, changes the thermal properties during the measurements and is a carrier of (predominantly latent) heat.

Therefore non-stationary, dynamic methods, sometimes also called transient methods, are most suitable for use in moist porous solids. With these methods it is recommended also to keep temperature differences between device and surroundings small, in accordance with the accuracy desired. Measurements over brief time intervals lower the influence of moisture movement.

Inhomogeneity of natural soil. Using eq. (3) or the calculation methods, a relatively large volume of soil is considered, with $\lambda$ and $\mathrm{C}$ constant over the volume. Blanc (1958), quoting Lettau, emphasizes however that the findings of various authors coincide with regard to the variation of the thermal conductivity and the heat capacity, up to an order of magnitude, within soil layers of a few centimeters thickness. This can certainly be considered the strongest warning as far as the root zone near the surface is concerned. Here the bulk-density is most irregular, in a horizontal as well as in a vertical direction, because of atmospheric and mechanical influences, which has its consequences for the thermal properties of even fairly flat bare soil (e.g. Chudnovskii, 1948). Still more important however is the moisture profile near the surface, coming into existence by means of precipitation, gravity discharge, changing water table depth, evaporation, capillary actions and temperature gradients, which result in flux densities of water, water vapour and energy.

The review of Wiegand and Taylor (1961) gives interesting data on the important evaporative part in shaping this moisture profile. In a homogeneous soil with a homogeneous moisture distribution, starting evaporation under isothermal conditions and at field capacity, a parabolic moisture distribution does arise after some time. When a sufficient number of surface sites become dry and the surface area, from which evaporation occurs, decreases, the evaporation comes into the first falling-rate stage. Finally the drying sites retire into the ground with further reduction of evaporation. 
Near the surface the moisture profile changes during this last stage of drying from convex to concave towards the surface, with the point of inflexion retiring inwards, as mentioned by Feodoroff and Rafi (1962). This evaporation within the soil is however limited to the first centimeters. Taking into account irregular precipitation and other changing atmospheric influences, predominantly effective as long as part of the surface is moist, it is clear how capricious and unpredictable the moisture profile may be near the surface of natural soil.

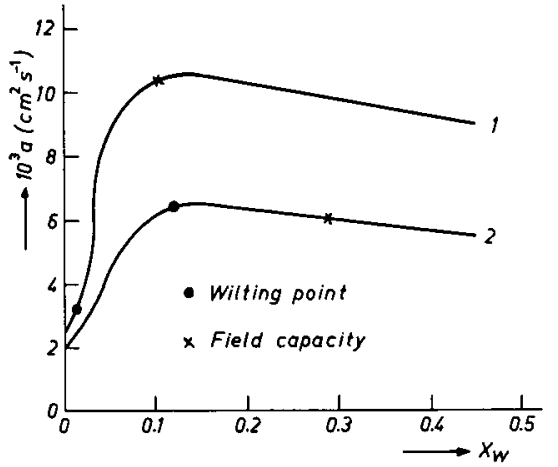

Fig. 1 Thermal diffusivity in relation to volumetric moisture content at normal soil temperature. Curve 1 for quartz sand, curve 2 for clay loam. Porosity for both soils 0.45. After de Vries (1959).

In view of the variability of thermal properties as $\lambda$, a and $b$ with moisture content, as e.g. measured by de Vries $(1952 \mathrm{a}, 1959)$, we have to conclude that no determination near or at the surface, making use of a solution of eq. (3), can give reliable results if the moisture content is lower than about ten volume percent (Fig. 1), except for completely dry soils. This includes for sandy soils the most important moisture range for agriculture, between field capacity and wilting point. The dependence on moisture is considerably less if the moisture content is larger over the entire profile.

Therefore the first $5 \mathrm{~cm}$ are an improper part of the soil for simple measurements by thermal methods. From roughly 5 to $20 \mathrm{~cm}$ the variation of moisture content with depth has usually become lower. Especially devices with a kind of space symmetry with respect to small moisture or density gradients may provide a useful answer. In deeper layers the moisture differences with depth will be small and changes with time will be almost the same at different depths.

Still two remarks have to be made about the thermal diffusivity. In the first place this parameter cannot be used as a soil moisture indicator, as two values of the previously calibrated curve may belong to one value of a (Fig. 1). Secondly it is not sufficient for the use of eq. (3) that $\mathrm{a}=\lambda(\mathrm{z}) / \mathrm{C}(\mathrm{z})$ is constant with depth. As $\lambda$ and $\mathrm{C}$ grow in the same direction with moisture content they tend to balance in a at values over 10 volume percent. But for such a case eq. (2) becomes:

$$
\mathrm{C}(\mathrm{z}) \frac{\delta \Theta(\mathrm{z}, \mathrm{t})}{\delta \mathrm{t}}=\frac{\delta}{\delta \mathrm{z}}\left\{\lambda(\mathrm{z}) \frac{\delta \Theta(\mathrm{z}, \mathrm{t})}{\delta \mathrm{z}}\right\}
$$

and eq. (3) now becomes: 
$\frac{\delta \Theta(\mathrm{z}, \mathrm{t})}{\delta \mathrm{t}}=\frac{1}{\mathrm{C}(\mathrm{z})} \frac{\delta \lambda(\mathrm{z})}{\delta \mathrm{z}} \frac{\delta \Theta(\mathrm{z}, \mathrm{t})}{\delta \mathrm{z}}+\frac{\lambda(\mathrm{z})}{\mathrm{C}(\mathrm{z})} \frac{\delta^{2} \Theta(\mathrm{z}, \mathrm{t})}{\delta \mathrm{z}^{2}}$

On account of the new term in eq. (5) as compared to eq. (3) an exact solution for the dynamic methods has only been obtained in a limited number of special cases.

Disturbance of the soil; Imperfect contact. All instruments modify the environment in which they are applied. As to the soil modifications in density, in water movement and thermal events (and related physical processes) are likely to occur. Therefore those transient methods are preferable which disturb least.

Related to this problem is the degree of contact between device and soil. In both cases, the effects on the results have to be detected experimentally. Sometimes it is possible to apply corrections by modifying the solution of eq. (3) for the surface thermal resistance.

Influence of moisture movement. The creation of a temperature gradient in the soil provokes a vapour distillation process, as mentioned above. This moisture redistribution, in turn, is partly opposed by capillarity. Again only experiment itself can give real information about the effect. This is one of the objections against the fully empirical methods of measuring moisture content by a thermal method from a calibration curve, without determining one of the thermal parameters. Extrapolating from the laboratory to the field especially the thermal regime in the soil differs and differences in moisture movement near the probes in use may easily occur. With this extrapolation one has also to be aware of possible differences in porosity.

The accuracy obtainable. The factors on which the reliability depends in measurements of thermal properties have now been reviewed. The accuracy can only be high if the use of the mathematical theory is justifiable and disturbing effects can be eliminated or detected. The accuracy in determining the moisture content depends on the relation between the parameters used and moisture content. For instance $\lambda$ is only well applicable as an indicator of the volumetric water fraction at low moisture contents. As we have seen above this is not possible at or near the surface.

Nevertheless the best method available for measuring moisture content by a thermal method, the cylindrical probe method, makes use of the thermal conductivity. Measurements with this needle-shaped instrument by de Vries and Peck (1958) needed a maximum temperature rise near the centre of the heating wire of less than one degree centigrade, the heating time being less than two minutes. Here a check on moisture movement does exist, an assessment can be made of the influence of the surface thermal resistance and there is a high degree of symmetry. When, for example, applied to a depth between 7 and $8 \mathrm{~cm}$ it gives a good idea about the average thermal conductivity between 5 and $10 \mathrm{~cm}$, with an accuracy better than $10 \%$. Applied deeper in the soil the accuracy may even be about $5 \%$. In sandy soils it may be used as a reliable indicator of moisture content between field capacity and wilting point. As the method asks for a skilled attention its application will be most useful in lysimeters or experimental irrigation plots.

In theory the most reliable parameter for moisture content indication is the contact coefficient $b$, as was first mentioned by Chudnovskii (1948). The dependence on moisture of $\lambda$ is intensified by that of $\mathrm{C}$. This might extend the moisture content region to which a thermal method can be applied. 
In search of a handy field method the late Prof. W. R. van Wijk developed the contact method, which determines the contact coefficient. On the ground of the given review this method will now be treated and the accuracy estimated.

\section{The contact method}

General remarks. The method makes use of a solution of the heat conduction equation (3) for two semi-infinite homogeneous bodies of different temperature conditions, suddenly brought into contact. From the temperature of the contact plane, recorded during the measurements, the $b$ of one homogeneous body (e.g. the soil near the surface) can be calculated if the $b$ of the other body (a block of appropriate material, placed on the soil) is known. Having a linear dependence of temperature on depth as an initial condition in the first centimeters of soil the heat flux density $\mathrm{H}$ can be determined from the slope of the course of the contact plane temperature, $\Theta(0, t)$, set out versus the square root of time (Fig. 2).

The method meets most of the necessary conditions. It is non-stationary and the soil need not be disturbed unless one is interested in the temperature profile. Further the derived mathematical solutions give the opportunity of correcting for imperfect contact (van Wijk, 1967) and for the position of the thermocouple near the surface of the block (Stigter, 1968), in such a way that they become of secondary importance for the measurements in the field.

As is clear from the above the method, which is applicable at the surface only, can't be used with volumetric water contents less than about 10 percent. Concerning determinations in the moisture region to which application is allowed the accuracy will come into question.

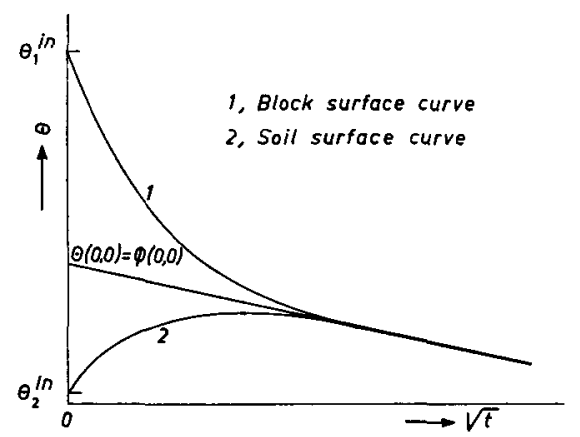

Fig. 2 Schematical diagram of the course of block surface and soil surface temperatures after placement, at $t=0$, of a block on a colder homogeneous dry soil. The temperature in the soil near the surface decreases linearly with depth.

The accuracy of the method. In the discussion on the accuracy it is sufficient to use a simple solution of eq. (3). This solution does not only depend on the boundary conditions, imposed by the block, but also on the initial temperature conditions in block and soil. The main difficulty is the mathematical expression for the initial temperature profile in the first centimeters of soil. Van Wijk tentatively used a linear temperature dependence on depth, and this was doubtless the best choice as all other possible expressions, e.g. an exponential one, are less suitable for use. 
In Fig. 2 the course of the experimental temperatures at the surfaces of the block and the colder soil is given schematically. The influence of imperfect contact is taken into account in the figure but may be ignored in the discussion. The straight line is given by:

$$
\Theta(0, \mathrm{t})-2(\pi)^{-1 / 2} \frac{\mathrm{E}_{2} \lambda_{2}}{\left(\lambda_{1} C_{1}\right)^{1 / 2}+\left(\lambda_{2} C_{2}\right)^{1 / 2}} \mathrm{t}^{1 / 2}=\frac{\Theta_{1}^{\text {in }}\left(\lambda_{1} C_{1}\right)^{1 / 2}+\Theta_{2}^{\text {in }}\left(\lambda_{2} C_{2}\right)^{1 / 2}}{\left(\lambda_{1} C_{1}\right)^{1 / 2}+\left(\lambda_{2} C_{2}\right)^{1 / 2}}
$$

Here $\mathrm{E}_{2}=\delta \Theta_{2}(\mathrm{z}, 0) / \delta \mathrm{z}=-\mathrm{H}_{2} / \lambda_{2}$ is the temperature gradient in the soil at $\mathrm{t}=0, \Theta_{1}$ in is the initial homogeneous block temperature and $\Theta_{2}{ }^{\text {in }}$ is the initial soil surface temperature. In the figure $\Theta_{2}{ }^{\text {in }}$ is higher than the temperatures within the soil. The sign of $\mathrm{z}$ is inverted at the plane $\mathrm{z}=0 . \emptyset(0, \mathrm{t})$ being the left hand side of eq. (6) we may write:

$\frac{\left(\lambda_{1} C_{1}\right)^{1 / 2}}{\left(\lambda_{2} C_{2}\right)^{1 / 2}}=\frac{\left(\varnothing(0, t)-\Theta_{2}{ }^{\text {in }}\right)}{\left(\Theta_{1}^{\text {in }}-\varnothing(0, t)\right)}=\frac{\left(\Theta(0,0)-\Theta_{2}{ }^{\text {in }}\right)}{\left(\Theta_{1}{ }^{\text {in }}-\Theta(0,0)\right)}$

By this extrapolation the use of an arbitrary point from the line in the diagram is avoided. Looking for the accuracy of $\lambda_{2} C_{2}$, relative to $\lambda_{1} C_{1}$ of the block material used, it thus is sufficient to know the inaccuracy in the three temperatures $\emptyset(0,0)=$ $\Theta(0,0), \Theta_{1}{ }^{\text {in }}$ and $\Theta_{2}$ in and in their differences.

As to $\Theta_{1}{ }^{\text {in }}$ this is only a matter of thermocouple calibration, $\Theta_{2}{ }^{\text {in }}$ and $\Theta(0,0)$ depend on the measurements. The reliability of $\Theta(0,0)$ is highly questionable if one is not sure of a really linear course of temperature with depth in the first centimeter of the soil, as this information is troubled by the highest influence of imperfect contact (Fig. 2).

Hence it was a fortunate condition that measurements of Derksen, of this laboratory, existed (W. J. Derksen, personal communication 1967), used for other purposes, which could partly be worked out for our purpose. The measurements included temperature recordings, every ten minutes, of thermocouples at $2,4,8$ and $16 \mathrm{~mm}$ at two and sometimes four different places in the neighbourhood of each other in homogeneous bare sand, clay and peat soil, exposed in the open. The main conclusion has to be that normally no linearity exists over the zone involved. Hence the measurements of $\mathrm{H}$ near the surface are inaccurate and the determination of $\mathrm{b}$ meets the best conditions when the gradient is expected to be lowest.

It can be estimated that even in this case $\Theta(0,0)$ will not be more accurately known than within $\pm 0.1^{\circ} \mathrm{C}$. The same accuracy holds at best for $\Theta_{2}$ in, measured with two blocks (van Wijk et al., 1967). Two equations are derived now from the mathematical solutions, with $\lambda_{2} \mathrm{C}_{2}$ and $\mid \Theta_{2}{ }_{2}$ unknown. In the laboratory this proved to be a success on dry soils. However the surface temperatures are supposed to be equal on the spots where the two blocks are placed. Moreover it can be shown that the accuracy decreases with the temperature difference between the two blocks. As the conclusion has to be drawn from the literature that $2^{\circ} \mathrm{C}$ is the upper limit allowed for the temperature difference $\Theta(0,0)-\Theta_{2}$ in in the soil, in order to prevent too much moisture movement, this sets a limit to the accuracy of $\Theta_{2}$ in . By employment of these values in eq. (7) a calculation can be made. This reveals that $\lambda_{2} C_{2}$ may be measured with an accuracy of approximately $25 \%$, relative to the value of $\lambda_{1} C_{1}$. 
For the clay loam soil of Fig. 1 for instance, the change of $\lambda \mathrm{C}$ between wilting point and field capacity, i.e. for moisture contents roughly between 10 and 30 volume percent, is somewhat more than $100 \%$ of the value at the wilting point. Therefore the accuracy of a single measurement seems too low for the use as an indicator of moisture content in the field from a calibration curve, even under the nearly isothermal conditions, which are, as explained, most suitable in the field.

\section{Discussion and conclusions}

In agreement with the problems outlined above, accurate results with the contact method have only been obtained on dry sandy soils and homogeneous solid material in the laboratory (Schneider, subm. for publ.; Stigier, 1968). Here high temperature differences may be used with homogeneous initial temperatures or an artificially induced linearly decreasing temperature. Under some arid conditions the situation of an extremely low homogeneously distributed moisture content in the upper soil layer may exist in the field. In this case the field accuracy may be somewhat higher than calculated above as the moisture transport under induced gradients will be low.

In general it can be said that in the field other thermal methods are, at best, of approximately the same accuracy for reasons mentioned in the given review, with the exception of the cylindrical probe method for light soils.

From the reviews of Höschele (1957) and de Vries (1959) it can be deduced that electrical resistance blocks and tensiometers are also showing considerable inaccuracies. For the near future the neutron scattering method, improved with regard to the loss of neutrons to the air when applied near the surface (within a depth of about $10 \mathrm{~cm}$ ), is perhaps most promising for field determinations.

Especially in behalf of irrigated fields, where a routine method, less laborious than the soil sampling method, is required, the problem of an adequate method has however not yet been solved.

\section{Acknowledgements}

I wish to express my gratitude to Dr. D. A. de Vries, Professor of physics at the University of Eindhoven, whose suggestions and remarks were of the highest value to me. I am also indebted to my colleague Drs. W. J. Derksen for placing at my disposal his previous measurements on soil temperatures and for reading and discussing the manuscript.

\section{References}

Blanc, M. L., 1958. The climatological investigation of soil temperature. W.M.O. Technical Note No. 20 in: W.M.O. - No. 72. T.P. 28, Geneva, 1-18.

Cary, J. W., 1967. The drying of soil: thermal regimes and ambient pressures. Agr. Meteorol., 4: $353-365$.

Chudnovskii, A. F., 1948. Fizika teploobmena $v$ pochve. (Translation from the Russian: 1962. Heat transfer in the soil. Israel Program for Scientific Translations, Jerusalem, $164 \mathrm{pp}$.)

Feodoroff, A. et Rafi, M., 1962. Evaporation de l'eau à partir d'un sol nu. Compt. rend. Acad. Sci., 255 : $3220-3222$ et $3468-3470$. 
Höschele, K., 1957. Untersuchungen zur Methode der elektrischen Bodenfeuchtemessung. Dissertation Landw. Hochschule, Hohenheim, $79 \mathrm{pp}$.

Lettau, H., 1954. Improved models of thermal diffusion in the soil. Trans. am. geophys. Union, $35: 121-132$.

Schneider, T., 1967. Nachtvorst en Microklimaat. Meded. Landbouwhogeschool, Wageningen, 67-4, $82 \mathrm{pp}$.

Schneider, T. New method for measuring heat flux density at the surface of soils and other solids. Prep. 1967, submitted for publication.

Stigter, C. J., 1968. On the possibility of determining thermal properties from contact-surface temperatures. Physica, 39 : 229-236.

Vries, D. A. de, 1952a. Het warmtegeleidingsvermogen van grond. Meded. Landbouwhogeschool, Wageningen, 52-1, $73 \mathrm{pp}$.

Vries, D. A. de, $1952 \mathrm{~b}$. The thermal conductivity of granular materials, Bull. Inst. intern. Froid, Annexe 1952-1 : 115-131.

Vries, D. A. de and Peck, A. J., 1958. On the cylindrical probe method of measuring thermal conductivity with special reference to soils. Austr. J. Phys., $11: 225-271$ and $409-423$.

Vries, D. A. de, 1959. Measurement of the moisture content of soils by thermal methods. Proc. 2nd Austr. conf. soil science, Melbourne, $68: 1-11$.

Wiegand, C. L. and Taylor, S. A., 1961. Evaporative drying of porous media. Special report 15 , Agr. Exp. Stat., Utah State Univ., Logan, $28 \mathrm{pp.}$

Wijk, W. R. van (Editor), 1963. Physics of Plant Environment. North Holland Publ. Comp., Amsterdam, $382 \mathrm{pp}$.

Wijk, W. R. van, 1964. Two new methods for the determination of the thermal properties of soil near the surface. Letter to the editor. Physica, 30: 387-388.

Wijk, W. R. van, 1967. New method for measuring heat flux density at the surface of soils or of other bodies. Nature, $213: 214$.

Wijk, W. R. van and Belghith, A., 1967. Determination of thermal conductivity, heat capacity and heat flux density in soils by non-stationary methods. In: W. E. Sopper and H. W. Lull (Editors), Proc. Int. Symp. Forest Hydr., Pennsylvania, 1965, Pergamon Press, Oxford, pp. 355-361.

Wijk, W. R. van, Schneider, T. et Belghith, A., 1967. Détermination des propriétés thermiques et du flux de chaleur à la surface du sol. Proc. Coll. Int. Phén. Transp. Chang. Ph., Paris, 1966, C.N.R.S., Paris, pp. 126-136.

Wijk, W. R. van and Schneider, T., 1967. Transfer and transformation of energy and mass in the soil. In: F. E. Eckardt (Editor), Functioning of terrestrial ecosystems of the primary production level. Proceedings of the Copenhagen Symposium 1965, UNESCO Nat. Resources Res. V, Paris, pp. 85-94. 